\title{
Proposta de método prático para avaliar o desempenho ambiental no ciclo de vida da construção
}

\begin{tabular}{|c|}
\hline VANDERLEY M. JOHN \\
\hline DANIEL COSTA REIS \\
\hline BEATRIZ MAFFINI GOMES \\
\hline CAROLINA STRABELLI SONVEZZO \\
\hline LIDIANE SANTANA OLIVEIRA \\
\hline
\end{tabular}

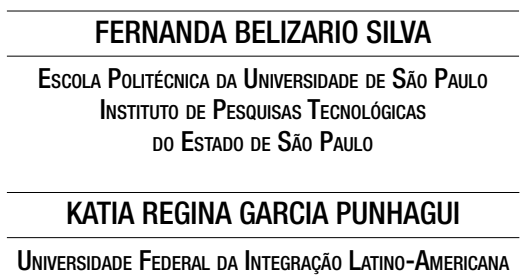

\begin{tabular}{c}
\hline LUCianA AlVES de OLiVEIRA \\
\hline Instituto de Pesquisas Tecnológicas \\
do Estado de São Paulo \\
\hline CLARICE DEGANI \\
\hline Conselho Brasileiro de Construção Sustentável
\end{tabular}

$\frac{\text { YAZMIN LISBETH MACK-VERGARA }}{\text { Universidad TeCnológica de PANAmá }}$

$\frac{\text { SÉRgiO AlMEIDA PACCA }}{\text { Escola de Artes, Ciências e Humanidades da Universidade de São Paulo }}$

\section{RESUMO}

APRESENTA-SE UM MÉTODO PARA GESTÃO DO DESEMPENHO AMBIENTAL NA INDÚSTRIA DA CONSTRUÇÃO, DECORRENTE DA SIMPLIFICAÇÃO DA AVALIAÇÃO DO CICLO DE VIDA (ACV), NO QUAL SÃO PRIORIZADOS OS INDICADORES DE CONSUMO DE

ENERGIA, DE ÁGUA E DE RECURSOS NATURAIS, GERAÇÃO DE RESÍDUOS SÓLIDOS E EMISSÃO DE $\mathrm{CO}_{2}$. O OBJETIVO DOS AUTORES É FORNECER UMA FERRAMENTA PRÁTICA DE GESTÃO AMBIENTAL NOS PROCESSOS DE DECISÃO DA CONSTRUÇÃO.

Palavras-chave: avaliação do ciclo de vida, desempenho ambiental, impactos ambientais da construção.

\section{INTRODUÇÃO}

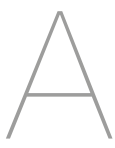

redução dos impactos ambientais é um dos desafios da atualidade, que depende de grandes transformações das cadeias industriais. O engajamento da cadeia da construção é fundamental, pois estima-se que o ciclo de vida do ambiente construído represente mais de 50\% do consumo de recursos naturais e da geração de resíduos sólidos, cerca de $36 \%$ do consumo de energia e 39\% das emissões de gases do efeito estufa associadas à energia e à indústria. Além disso, os edifícios consomem uma grande parcela da água em regiões urbanas.
A redução dos impactos ambientais exige que os profissionais da indústria disponham de ferramentas de suporte à decisão, que permitam de maneira prática quantificar impactos, estabelecer prioridades e metas, monitorar e comunicar os avanços. Como melhorias parciais não necessariamente levam à redução do impacto total, a ferramenta deve considerar o ciclo de vida completo e a vida útil dos materiais e das edificações. Além disso, para evitar que a busca pela redução de um impacto leve ao aumento despercebido de outros, a ferramenta precisa avaliar diversos impactos ambientais, simultaneamente.
Por exemplo: o uso de agregados reciclados para a produção de concreto reduz o consumo de recursos naturais. Entretanto, caso seja necessário aumentar o teor de cimento do concreto para obter um desempenho mecânico adequado, o uso do agregado reciclado vai ter um potencial de aquecimento global superior ao do concreto com agregados virgens, visto que a produção de cimento implica na emissão de $\mathrm{CO}_{2}$, o principal gás de efeito estufa. Além disso, caso o produto com menor impacto de produção tenha uma vida útil menor que o de referência em determinado ambiente, o impacto ambiental ao longo 
da vida útil de projeto da edificação pode ser maior do com o produto tradicional, visto que reparos e substituições serão necessários ao longo da vida útil, gerando resíduos e consumindo novos materiais, com impactos ambientais correspondentes.

A Avaliação do Ciclo de Vida (ACV) é um método que avalia quantitativamente diversos impactos ambientais ao longo do ciclo de vida de um produto. No caso da construção, esse ciclo inclui a extração de recursos naturais, a fabricação dos materiais de construção, seu transporte, a construção, o uso e manutenção da edificação, sua demolição e a dis- posição final dos resíduos. Em todas as atividades, os fluxos de materiais e energia devem ser quantificados (Figura 1). A seguir, esses fluxos são convertidos em indicadores de impacto ambiental, expressos em relação a uma unidade funcional. Por exemplo, os fluxos de gases de efeito estufa $\left(\mathrm{CO}_{2}, \mathrm{CH}_{4}, \mathrm{~N}_{2} \mathrm{O}\right.$, etc.) são convertidos no indicador de potencial de aquecimento global, que pode ser expresso em kg de $\mathrm{CO}_{2}$ equivalente/ (m²ano) para um edifício ("m²*ano" é a unidade funcional).

A realização do inventário de ciclo de vida completo de um produto exige medir e organizar uma grande quantidade de dados, englobando toda a cadeia de suprimentos. A estimativa das 16 categorias de impacto ambiental requeridas pela nova norma europeia de EPD (Environmental Product Declaration) de produtos de construção EN 15804 exige medir milhares de substâncias por período representativo. Muitos desses impactos têm pouca ou nenhuma relação direta com a cadeia da construção (ex. radiação ionizante) (SILVA et al., 2020b). Por outro lado, impactos ambientais relevantes para a construção não são considerados nessa norma, como a escassez local de minerais como areia e calcário. Tudo isto faz

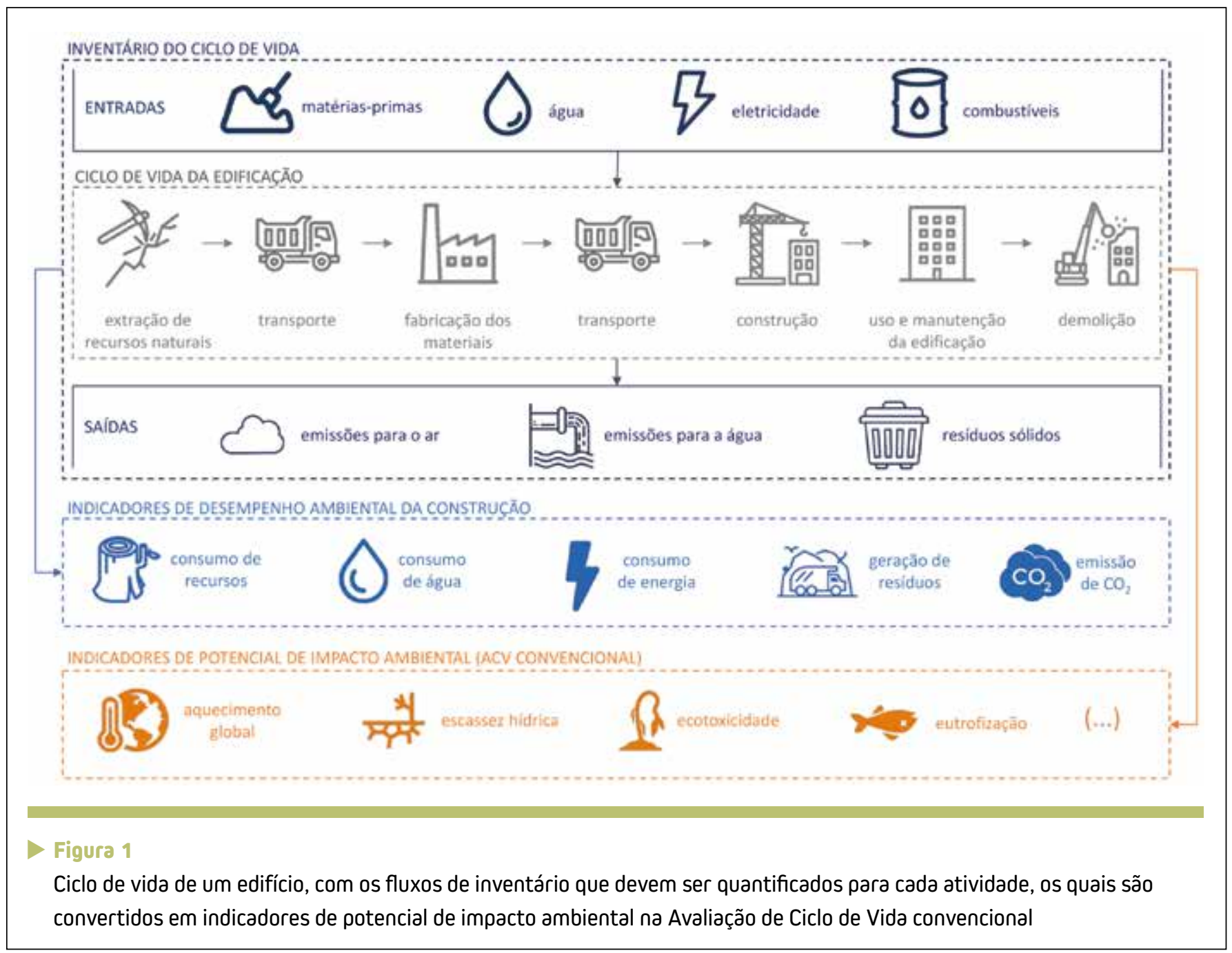




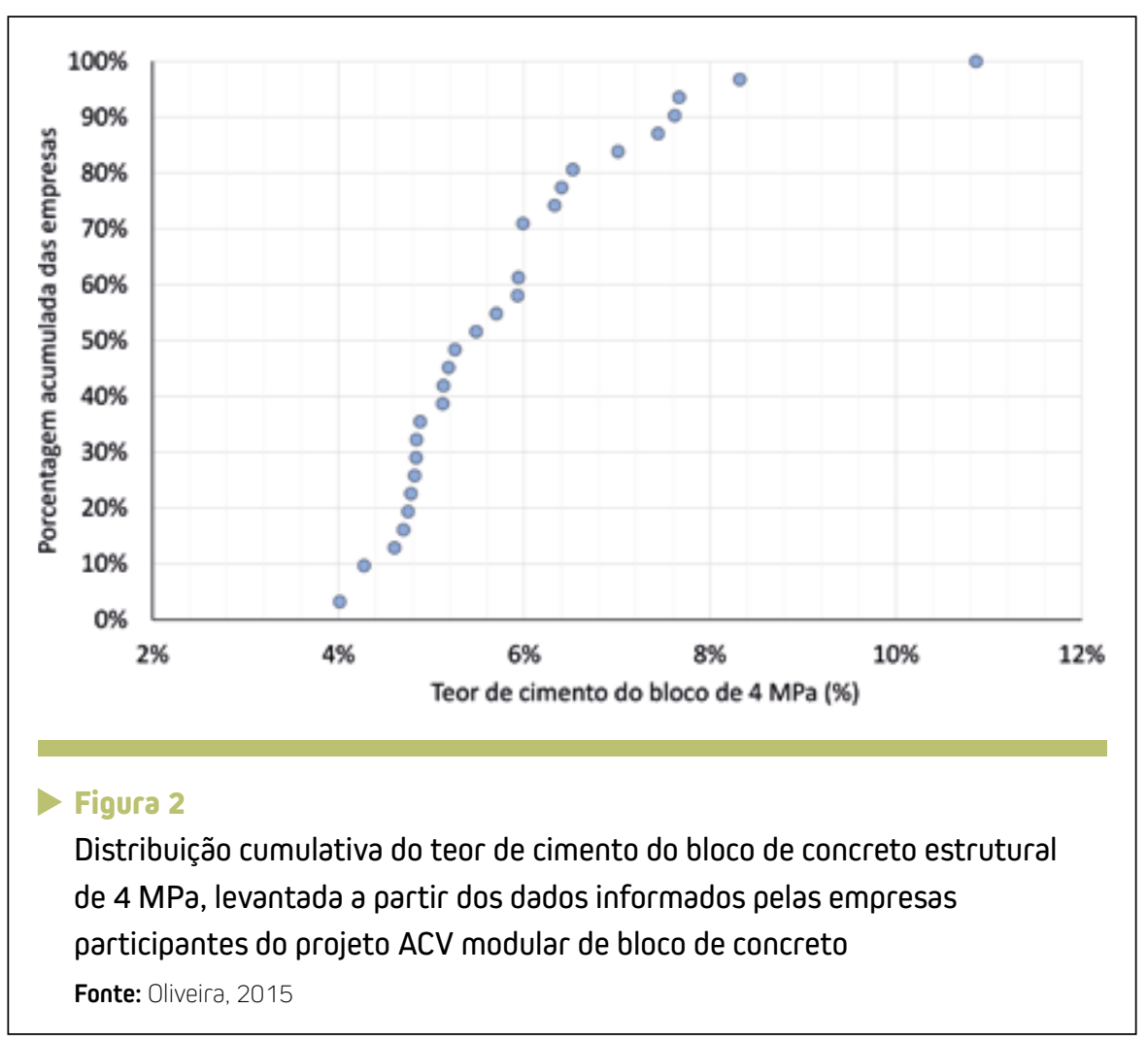

da ACV uma ferramenta complexa, especializada, demorada, cara, muito útil mas pouco adequada para as decisões do dia a dia.

Para facilitar a ACV, a medição dos fluxos de inventário é frequentemente substituída pela coleta de informações disponíveis em bases de dados secundários, medidos majoritariamente na Europa. Esta prática assume que cada produto tem um impacto típico, desde que produzido com mesma rota tecnológica e matriz energética. Assume-se, erroneamente, que diferenças entre fabricantes do mesmo produto, suas práticas de gestão, equipes e detalhes da composição de suas matérias-primas são pouco relevantes. Com isso, a ACV restringe a decisão à escolha de um produto em detrimento de outro e aos fabricantes brasileiros de blocos de concreto comparar seu desempenho ambiental ao dos concorrentes e estabelecer metas realistas para redução do seu impacto ambiental.

Esse exemplo demonstra a importância de avaliar os impactos ambientais da construção com base em dados locais e representativos. Este artigo apresenta uma proposta de método prático e acessível para avaliar o desempenho ambiental da construção, que mantém as características positivas da ACV: sua abordagem quantitativa, a consideração de múltiplos impactos ambientais e de todo o ciclo de vida da construção.

\section{PROPOSTA DO MÉTODO DE AVALIAÇÃO DO DESEMPENHO AMBIENTAL}

A proposta de um método simples baseado na ACV surgiu no Grupo de Trabalho de Materiais do Conselho Brasileiro de Construção Sustentável (CBCS) há alguns anos sob o nome de "ACV Modular". Uma aplicação piloto foi realizada por 33 empresas fabricantes de blocos de concreto reunidas na Bloco Brasil, com apoio da Associação Brasileira de Cimento Portland (ABCP), da Universidade de São Paulo (USP) e do CBCS ${ }^{1}$.

O desenvolvimento do método considerou: os aprendizados desse projeto piloto; uma análise aprofundada da ACV convencional para produtos de construção (SILVA et al., 2020b); e a experiência do levantamento de dados de ACV para elaboração de inventários de ciclo de vida de cimentos e concretos brasileiros (SILVA et al., 2020a), incluindo as 
dificuldades observadas nesse processo. Observa-se, no entanto, que a proposta aqui apresentada é uma primeira versão do método, cujo desenvolvimento futuro deve se dar em parceria com o setor da construção civil nacional, órgãos estatais e academia. Ou seja, é um ponto de partida.

\section{I Os 10 princípios}

Os seguintes princípios norteiam o desenvolvimento do método de avaliação do desempenho ambiental do ciclo de vida da construção:

\section{Priorizar os impactos ambien-} tais mais urgentes do setor e da sociedade, especialmente aqueles que não são controlados por regulamentações em vigor (ex.: limites para emissão de poluentes);

\section{Manter a perspectiva do ciclo} de vida, seja de um produto, seja do edifício, analisando múltiplos impactos, referenciados em uma unidade funcional relevante (ex: $\mathrm{kg} \mathrm{CO}_{2} /\left(\mathrm{m}^{2 *} \mathrm{ano}\right)$ para mensurar as emissões de $\mathrm{CO}_{2}$ ao longo do ciclo de vida de um edifício);

3. Ser universal e adaptável, com indicadores de desempenho ambiental normatizados e aplicáveis a todos os materiais, construções, de pequenas a grandes empresas, e até cidades, subsidiando diferentes políticas públicas e ações setoriais;

4. Permitir diferenciar empresas, uma vez que diferentes fabricantes de um mesmo produto têm impactos ambientais diferentes;

5. Viabilizar benchmarks setoriais, permitindo que empresas comparem o seu desempenho, o que requer um método simples e viável para pequenas e grandes empresas;
6. Privilegiar dados primários, com todos os fluxos dos processos diretamente controlados pela empresa medidos e verificáveis. Como todos medem seus fluxos diretos, a necessidade de dados secundários (ou genéricos) é reduzida;

7. Explicitar a incerteza de dados genéricos. Dados genéricos são necessários nas fases iniciais de projeto, quando fornecedores de materiais e mesmo especificações técnicas ainda não estão definidos. Portanto, esses dados devem refletir a faixa de variação do impacto esperada entre os fabricantes dos materiais e as incertezas relativas à indefinição das especificações;

8. Facilitar a compreensão. Os resultados devem ser facilmente entendidos por todos os interessados, facilitando a comunicação e promovendo o engajamento;

9. Integrar sistemas de gestão. Para que haja uma evolução efetiva, critérios ambientais precisam integrar as informações de rotina utilizadas por gestores em suas decisões. Isto requer indicadores facilmente mensuráveis e verificáveis, com mínimo uso de equipamentos ou especialistas;

10.Promover a melhoria contínua, por meio de indicadores simples, de rápida atualização e associados a benchmarks setoriais, com vistas a monitorar a evolução contínua do setor.

\subsection{Os indicadores de desempenho ambiental}

O método proposto contempla cinco indicadores de desempenho ambiental, que são simples de medir e representam as principais preocupações ambientais da sociedade e do setor da construção (WBCSD, 2016), quais sejam:

- Consumo de energia (expresso em MJ);

- Consumo de água (expresso em litros ou $\mathrm{m}^{3}$ );

- Consumo de recursos (exceto água e energia) (expresso em kg);

- Geração de resíduos (expressa em kg);

- Emissão de $\mathrm{CO}_{2}$ (expressa em kg). Com este conjunto de indicadores, é possível promover as principais mudanças necessárias visando ao desenvolvimento sustentável da construção: combater as mudanças climáticas, pois $\mathrm{O} \mathrm{CO}_{2}$ é o principal gás de efeito estufa emitido nas atividades da construção; aumentar a eficiência energética, para facilitar a transição para energias renováveis, inclusive em processos industriais; reduzir o consumo de água, reduzindo o stress hídrico que deve ser agravado com a mudança do clima; desmaterializar a construção e aumentar a eficiência no uso de recursos, pois sua extração e beneficiamento está associada a diversos impactos ambientais; e reduzir a quantidade de resíduos de construção e demolição, reduzindo os custos dos municípios, o volume de aterro e promovendo a circularidade.

Esses indicadores, importantes e simples de medir, podem ser integrados ao sistema de gestão de empresas e continuamente atualizados. No futuro deverão ser incorporados a plataformas ERP (Enterprise Resource Planning) e BIM (Building Information Modelling) automatizando o cálculo. O monitoramento destes 
indicadores não requer equipamentos complexos e dispensa a contratação de consultores especializados. Caso seja necessário, uma cadeia de valor pode incluir nos seus produtos indicadores adicionais relevantes como, por exemplo, a emissão de compostos orgânicos voláteis para tintas e adesivos.

A principal diferença entre o método proposto e a ACV convencional é a quantidade e a complexidade dos indicadores a serem calculados. Cada indicador de desempenho ambiental requer uma quantidade de dados de inventário, o que implica em custos e tempo para realizar esse levantamento. Por isso, optou-se por focar nos aspectos ambientais mais relevantes para a construção. Além disso, a literatura mostra que muitos impactos são correlacionados com o consumo de energia, de forma que os cinco aspectos consideram, indiretamente, outros impactos ambientais. Cabe ressaltar que o método proposto não se opõe à ACV convencional, sendo que as mesmas informações podem ser integradas ao inventário de uma ACV completa em uma abordagem evolutiva.

Como a simplificação torna a avaliação do desempenho ambiental baseada em dados primários acessível a todas as empresas e profissionais, as chances de que estes passem usar estas informações para selecionar fornecedores crescem. O mercado então passaria a incentivar que empresas com maior impacto ambiental busquem adotar ações de mitigação, em um círculo virtuoso.

A seguir, são detalhados cada um dos indicadores que integram o méto-

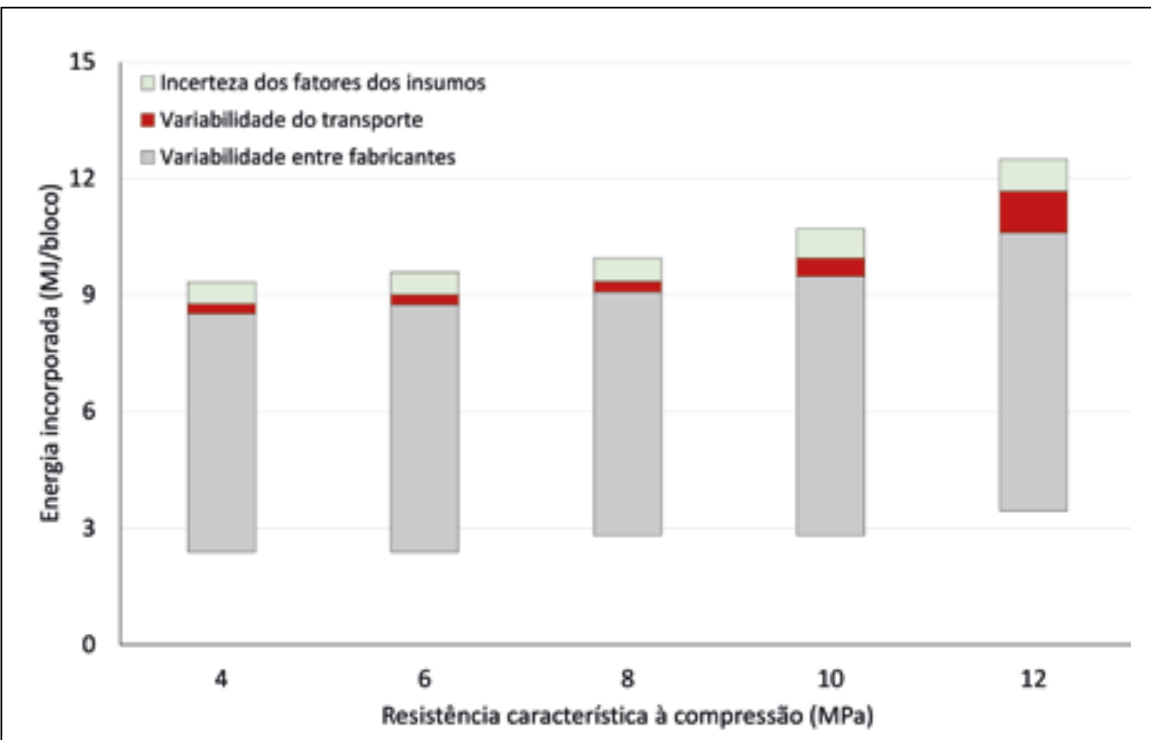

Figura 3

Faixa de consumo de energia para a produção de uma unidade de bloco de concreto para alvenaria estrutural, apresentada por classe de resistência à compressão do bloco. Os valores consideram desde a extração de recursos naturais até a produção do bloco

Fonte: Oliveira, 2015 do, juntamente com alguns exemplos de pesquisas feitas pelos autores utilizando o método proposto.

\section{2.己.I CONSUMO DE ENERGIA}

O indicador de consumo de energia (também conhecido como "Demanda Acumulada de Energia") contabiliza a energia primária, ou seja, a energia extraída da natureza que é consumida no ciclo de vida de um produto, expressa em mega joules (MJ). O cálculo do consumo de energia considera o consumo de combustíveis, tanto fósseis quanto renováveis, bem como de energia de origem solar, eólica, hidráulica, geotérmica e nuclear. A energia dos combustíveis é calculada multiplicando-se a quantidade consumida (ex.: L) pelo poder calorífico do combustível (ex.: MJ/L). A energia das demais fontes é considerada com eficiência de conversão de 1:1 (ex.: $1 \mathrm{MJ}$ de energia hidráulica disponível para uso = $1 \mathrm{MJ}$ de energia primária). No caso da energia elétrica do Sistema Interligado Nacional, deve-se considerar a eficiência na conversão de energia das usinas termoelétricas. Recomenda-se expressar as parcelas de energia renovável e não renovável do consumo de energia, para promover o uso de fontes renováveis.

A Figura 3 apresenta o indicador de consumo de energia para a produção de blocos de concreto para alvenaria estrutural, desde a extração dos recursos naturais até a produção do bloco na fábrica. As barras representam as faixas de valores possíveis de consumo de energia, considerando as variações entre os fabricantes de blocos de concreto (traço, a 
massa dos blocos e o consumo energético de cada fábrica) e as variações nas atividades que antecedem a fabricação de blocos (por exemplo, transporte das matérias-primas). Os resultados mostram que a demanda acumulada de energia pode variar mais de 3 vezes para o mesmo produto e que a principal razão para essa variação são as diferenças entre fabricantes, sobretudo no teor de cimento (OLIVEIRA, 2015). Por exemplo, para o bloco de resistência característica à compressão de $4 \mathrm{MPa}$, o consumo de energia pode variar, grosso modo, entre 3 e $9 \mathrm{MJ} / \mathrm{bloco}$, sendo que $88,5 \%$ dessa variação se deve a diferenças entre fabricantes.

\section{2.己 Consumo de ÁGUA}

O indicador de consumo de água contabiliza toda a água que é extraída da natureza para realizar um determinado processo, menos a quantidade de água retornada à natureza com qualidade igual ou melhor, em $\mathrm{m}^{3}$ ou L. Desse modo, o consumo inclui a água que é tornada indisponível, ou seja, a água incorporada a um produto (ex.: concreto), a água consumida para uso humano e retornada como esgoto (ou seja, com qualidade inferior) e a água evaporada. Não é incluída no consumo, por exemplo, a água extraída de um rio utilizada no resfriamento de um processo industrial, que é retornada ao mesmo rio (embora com uma temperatura maior).

A Figura 4 mostra a faixa de variação esperada no consumo de água da produção de $1 \mathrm{~m}^{3}$ de concreto, desde a extração de recursos naturais até o portão da central de concreto, a partir de dados de literatura

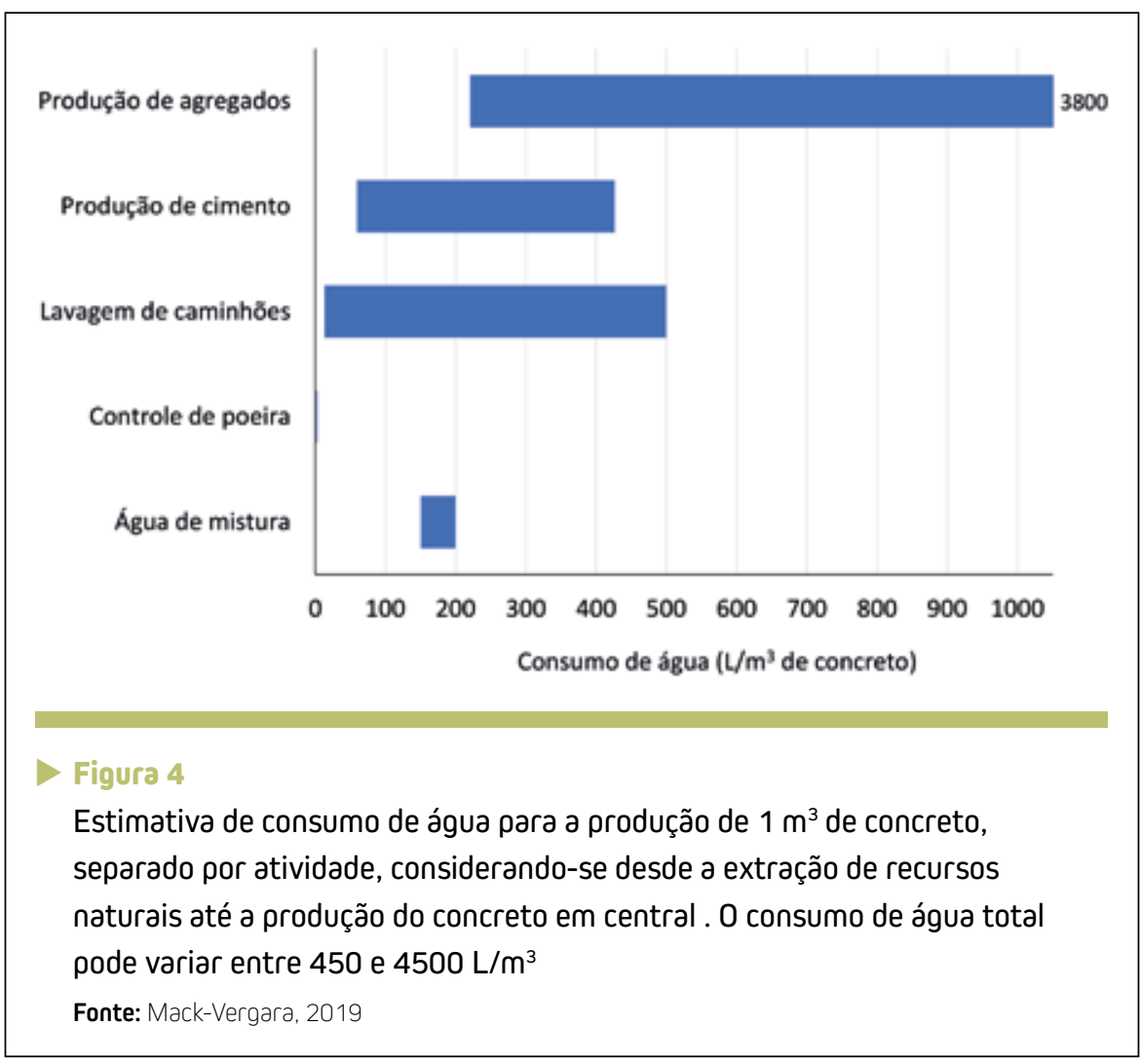

(MACK-VERGARA, 2019). A grande variabilidade é devida tanto a aspectos tecnológicos - lavar ou não agregados, por exemplo - quanto a diferenças metodológicas entre estudos na elaboração do inventário, o que reforça a importância de um método normatizado.

\subsubsection{Consumo de RECURSOS}

O consumo de recursos é calculado pela soma de todos os recursos utilizados como matéria-prima ao longo do ciclo de vida de um material ou edifício, com exceção da água, para que não haja dupla contagem. $O$ indicador é expresso em $\mathrm{kg}$. Ele inclui recursos renováveis (ex.: madeira plantada) e não renováveis (ex.: calcário) - importante notar que madeira nativa originária de desmatamento é considerada um recurso não renovável. Além disso, o indicador considera tanto o consumo de recursos virgens quanto reciclados, pois embora os recursos virgens representem a maior preocupação ambiental quanto ao esgotamento de recursos naturais, a simples substituição desses recursos por materiais reciclados não leva necessariamente a uma maior eficiência no uso de recursos pela construção e entende-se que ambas as ações são necessárias. Recomenda-se, no entanto, apresentar as parcelas de recursos virgens e reciclados, renováveis e não renováveis do indicador de consumo de recursos.

O indicador de consumo de recursos também considera os fluxos ocultos, ou "hidden flows", que são materiais removidos durante os processos de extração que não tem valor econômico e que normalmente não deixam o local de produção, não sendo usualmente contabilizados pelas 
empresas. Fluxos ocultos incluem $\mathrm{O}$ solo superficial (material estéril) e a vegetação removida para acesso à extração mineral, por exemplo. Apesar de "ocultos", esses fluxos representam quantidades significativas de material.

A Figura 5 apresenta os dados de consumo de recursos para a produção de blocos estruturais de concreto, considerando todas as atividades até o portão da fábrica de blocos (OLIVEIRA, 2015). Os dados incluem o uso direto de recursos e o uso de recursos na produção do cimento (incluindo resíduos), mas não os resíduos gerados na produção dos agregados. Observa-se que existe uma variação de 2 kg/bloco, cerca de $15 \%$ da massa, para blocos com mesma classe de resistência. Tal variação se deve principalmente a diferenças de dosagem e da espessura de paredes dos blocos. Isso revela um potencial de desmaterialização do bloco de concreto sem prejuízo ao seu desempenho.

\subsubsection{GERAÇ̃̃O DE RESÍDUOS}

De acordo com a Política Nacional de Resíduos Sólidos (PNRS), resíduo sólido é todo material, substância, objeto ou bem descartado resultado de atividades humanas, a cuja destinação final se procede ou se está obrigado a proceder. A destinação final inclui não somente a disposição final (por exemplo, em aterros sanitários), mas também a reutilização, a reciclagem, a compostagem e o aproveitamento energético. Rejeito são resíduos que não apresentam possibilidade de recuperação técnica e economicamente viável e que, por-

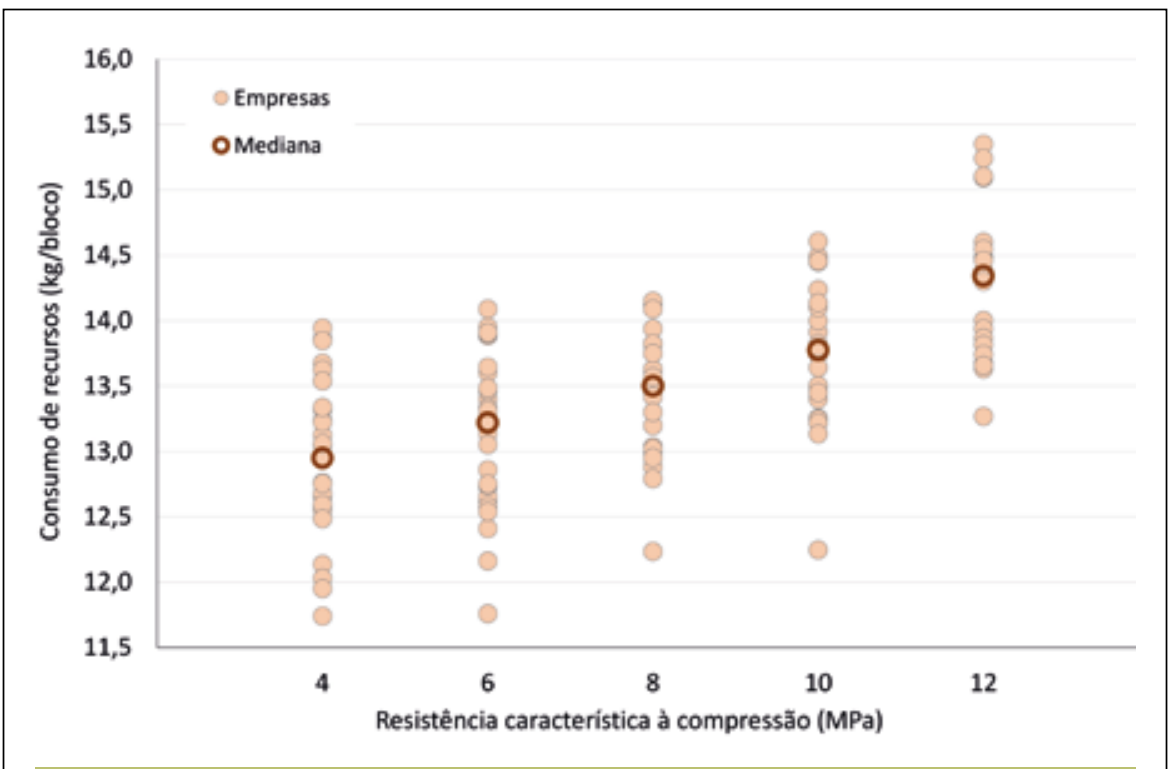

Figura 5

Consumo de recursos para produção de blocos estruturais de concreto, expresso por classe de resistência à compressão do bloco. Observa-se que o consumo varia cerca de $2 \mathrm{~kg}$ para um mesmo tipo de bloco, o que representa aproximadamente $15 \%$ da sua massa

Fonte: Oliveira, 2015 tanto, devem ser dispostos de forma ambientalmente adequada.

O indicador de geração de resíduos inclui a soma da quantidade de resíduos sólidos gerados ao longo do ciclo de vida de um material ou edifício, em massa $(\mathrm{kg})$, independentemente desse resíduo ter um valor econômico para eventual reaproveitamento - um fabricante não se dispõe a ampliar sua fábrica para atender um crescimento da demanda por um resíduo. Ele inclui perdas nos processos de extração de recursos naturais (inclusive fluxos ocultos), de fabricação de materiais e no canteiro de obras, bem como a demolição do edifício ou de suas partes. Recomenda-se expressar a parcela da geração de resíduos conforme a destinação, para promover o reuso e a reciclagem.

A Figura 6 apresenta uma estimativa inicial do consumo de recursos e geração de resíduos típicos para produzir argamassa no Brasil (REIS; MACK-VERGARA; JOHN, 2019). Para cada metro cúbico de argamassa aplicada (com $\left.2100 \mathrm{~kg} / \mathrm{m}^{3}\right)$, são consumidos $6165 \mathrm{~kg}$ de recursos, incluindo: $1541 \mathrm{~kg}$ de perdas em obra (tanto incorporadas quanto as que viram resíduo); 986 L de água consumidos na produção de ligante e extração de areia; 678 kg de estéril, ou seja, de recursos extraídos nas jazidas de calcário (para cimento e cal) e areia e não aproveitados; 678 kg de rejeitos de mineração de areia; e 185 kg de recursos que são transformados em $\mathrm{CO}_{2}$ na calcinação do cimento e da cal, ou em água. É claro, esses valores variam significativamente dependendo das práticas das empresas. 


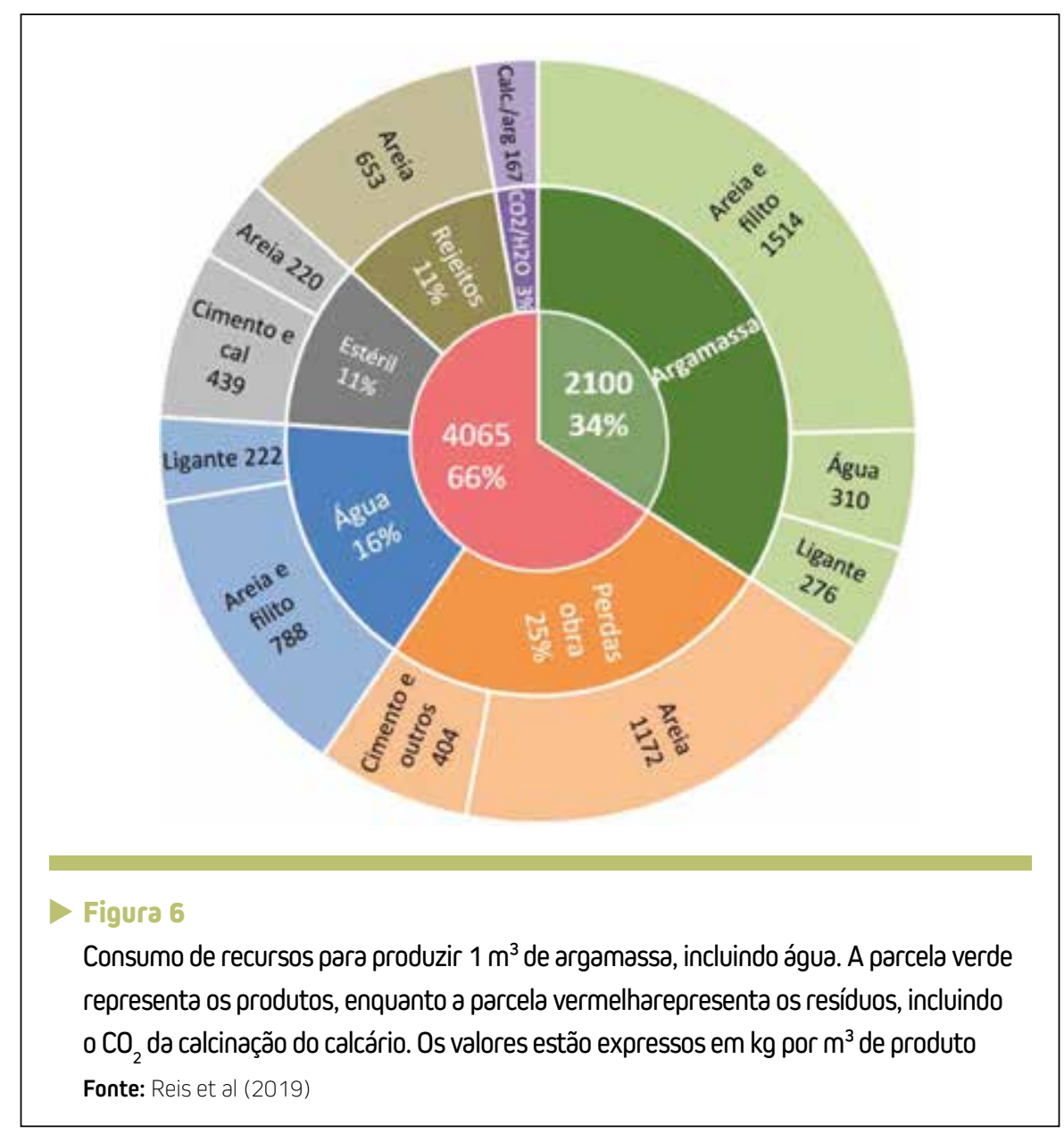

\subsubsection{EMISSÃo DE CO}

$\mathrm{O}$ indicador de emissão de $\mathrm{CO}_{2}$, expresso em $\mathrm{kg}$, considera a soma das emissões de $\mathrm{CO}_{2}$ decorrentes do consumo de combustíveis fósseis e de emissões diretas de processos químicos, por exemplo a descarbonatação do calcário na produção de cal e cimento. As emissões de $\mathrm{CO}_{2}$ dos combustíveis podem ser estimadas pelo consumo (ex.: L) multiplicado por fatores de emissão (ex.: $\mathrm{kg} \mathrm{CO}_{2} / \mathrm{L}$ ). $\mathrm{O}$ $\mathrm{CO}_{2}$ emitido a partir de fontes renováveis (biomassa) é considerado neutro, excluída a madeira nativa não manejada. Observa-se que, como parte da energia elétrica é produzida por termelétricas movidas a combustíveis fósseis, o consumo de eletricidade evidencia o papel da dosagem otimizada do concreto na mitigação dos impactos ambientais.

\section{PRÓXIMOS PASSOS}

O presente artigo apresenta uma primeira proposta do que se considera um método de avaliação do desempenho ambiental que pode ser implementado de forma prática e em larga escala pela indústria da construção. Entende-se, porém, que a proposta desse método deve ser uma construção conjunta, com a participação da indústria da construção, do poder público, da academia e da sociedade.

Será necessário um esforço considerável para definir, detalhar e implantar de forma coordenada uma metodologia prática para avaliação e melhoria do desempenho ambiental da construção brasileira. Isto não será possível sem o investimento de empresas e o engajamento de associações setoriais e profissionais. É certo que os benefícios para a competitividade do setor e para o futuro da sociedade superam em muito os custos dessa iniciativa.

Este processo passa pela produção de um conjunto normativo coerente que dê suporte para a elaboração de benchmarks setoriais por produto e de declarações ambientais de produto por empresa. Isso requer desenvolver e manter uma base de dados brasileira. Esta base de dados deverá ser integrada aos softwares BIM, automatizando e reduzindo o custo da avaliação ambiental, orientando decisões de projeto. Para incentivar a elaboração de declarações ambientais de produto, as certificações de sustentabilidade de edifícios precisam reconhecê-las, tal como hoje reconhecem declarações 


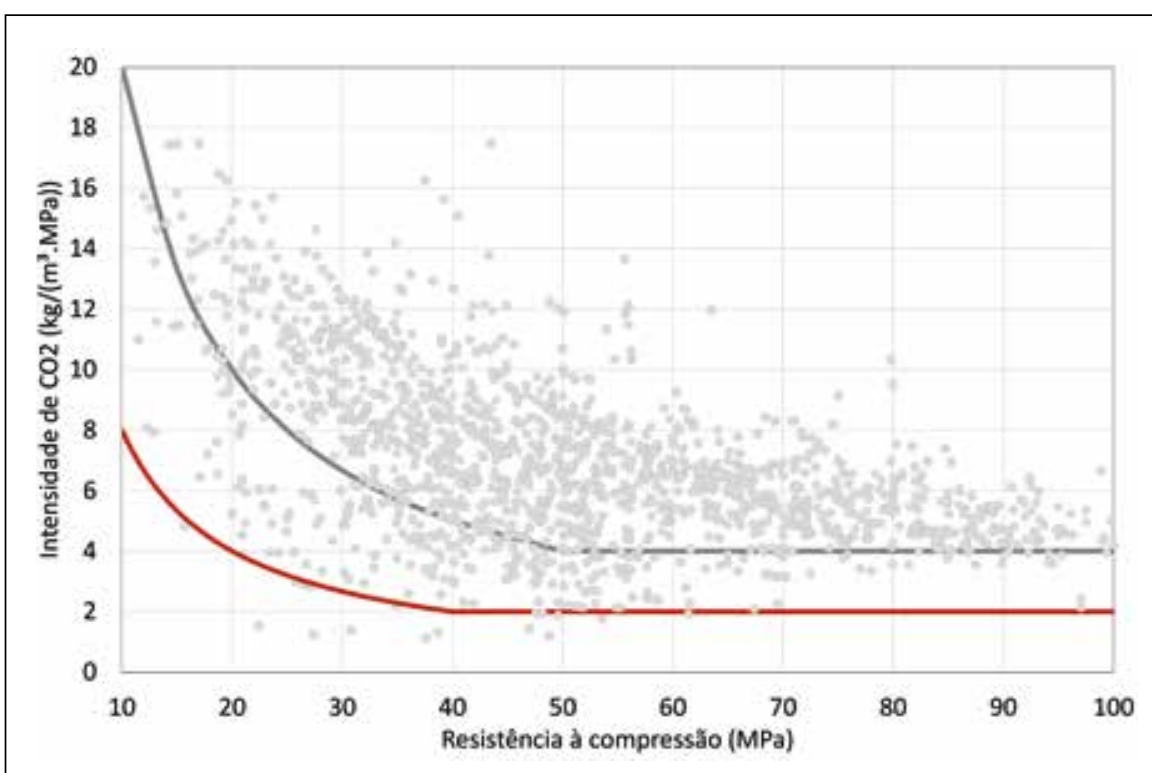

Figura 7

Benchmark da intensidade de $\mathrm{CO}_{2}$ do concreto, calculado em $\mathrm{kg} \mathrm{CO}_{2} /\left(\mathrm{m}^{3} . \mathrm{MPa}\right)$, a partir de dados nacionais e internacionais. A linha cinza é o limite mínimo de emissão de $\mathrm{CO}_{2}$ de concretos com cimento sem adições. A vermelha, 0 limite mínimo de $\mathrm{CO}_{2}$ de concretos feitos com cimentos com adições

Fonte: Damineli, 2013

baseadas na ACV convencional, inacessível para parte do mercado. A formação dos recursos humanos, tanto da academia quanto profissionais atuantes no mercado, é urgente. Neste sentido a equipe já está oferecendo uma pri- meira edição de um curso de extensão USP gratuito com participantes de todo o Brasil.

Acredita-se que a simplificação da avaliação de desempenho ambiental vai democratizar o acesso à informa- ção ambiental relevante, permitirá gerar benchmarks setoriais de desempenho ambiental de materiais e de soluções de projeto, colaborando para criar um círculo virtuoso, posicionando a construção civil como setor chave para promoção do desenvolvimento sustentável.

\section{AGRADECIMENTOS}

À Associação Brasileira da Indústria de Blocos de Concreto (Bloco Brasil), à Associação Brasileira de Cimento Portland (ABCP) e ao Conselho Brasileiro de Construção Sustentável (CBCS), pela colaboração na coleta de dados primários de ciclo de vida no projeto ACV Modular de Blocos e Pisos de Concreto, e aos fabricantes de cimento e concreto que participaram da coleta de dados de ACV para elaboração dos inventários de ciclo de vida brasileiros. À Capes pelo financiamento das pesquisas de Lidiane Oliveira e Beatriz Gomes. Ao INCT CEMTec Tecnologias Cimentícias Ecoeficientes Avançadas, financiado pelo CNPq (485340/2013-5) e FAPESP (2014/50948-3).

\section{>REFERÊNCIAS BIBLIOGRÁFICAS}

[1] ATHENA SUSTAINABLE MATERIALS INSTITUTE. A Canadian Industry-Average Cradle-to-Gate Life Cycle Assessment of Two Concrete Masonry Unit Products - EPD Project Report. Canadá: CCMPA Canadian Concrete Masonry Producers Association; ASTM International, 2016. Disponivel em: <http://www.athenasmi.org/wpcontent/uploads/2016/10/CCMPA_Industry_Average_C2G_LCA_CMU.pdf >. Acesso em: 10 nov. 2020.

[2] DAMINELI, B. L. Conceitos para formulação de concretos com baixo consumo de ligantes: controle reológico, empacotamento e dispersão de partículas. Tese (Doutorado) - Escola Politécnica, Universidade de São Paulo, São Paulo, 2013.

[3] MACK-VERGARA, Y. L. Concrete water footprint: a streamlined methodology.Tese (Doutorado) - Escola Politécnica, Universidade de São Paulo, São Paulo, 2019.

[4] OLIVEIRA, L. S. Avaliação do ciclo de vida de blocos de concreto do mercado brasileiro: alvenaria e pavimentação. Dissertação (Mestrado) - Escola Politécnica, Universidade de São Paulo, São Paulo, 2015.

[5] REIS, D. C.; MACK-VERGARA, Y. L.; JOHN, V. M. Material flow analysis and material use efficiency of Brazil's mortar and concrete supply chain. Journal of Industrial Ecology, v. 23, n. 6, p. 1396-1409, 2019.

[6] SILVA, F. B. et al. AVALIAÇÃO DO CICLO DE VIDA DO CONCRETO DOSADO EM CENTRAL COM BASE EM DADOS DA INDÚSTRIA BRASILEIRA. CONCRETO \& Construções, v. XLVIII, n. 98, p. 91-97, 2020a.

[7] SILVA, F. B. et al. Primary data priorities for the life cycle inventory of construction products: focus on foreground processes. The International Journal of Life Cycle Assessment, v. 25, n. 6, p. 980-997, jun. 2020b.

[8] WORLD BUSINESS COUNCIL FOR SUSTAINABLE DEVELOPMENT. The Business Case for the Use of Life Cycle Metrics in Construction \& Real Estate. Genebra, WBCSD, 2016. Disponivel em: <https://www.wbcsd.org/contentwbc/download/1930/24581>. Acesso em 18 abr. 2020. 